\title{
Expression of Protein Kinase C Inhibitor Blocks Cerebellar Long-Term Depression without Affecting Purkinje Cell Excitability in Alert Mice
}

\author{
Jeroen Goossens, ${ }^{1,2}$ Hervé Daniel, ${ }^{3}$ Armelle Rancillac, ${ }^{3}$ Johannes van der Steen, ${ }^{1}$ John Oberdick, ${ }^{4}$ \\ Francis Crépel, ${ }^{3}$ Christiaan I. De Zeeuw, ${ }^{5}$ and Maarten A. Frens ${ }^{1}$ \\ ${ }^{1}$ Department of Physiology, Neuroscience Institute, Erasmus University Rotterdam, 3000 DR Rotterdam, The \\ Netherlands, 2 Department of Medical Physics and Biophysics, University of Nijmegen, 6500 HB Nijmegen, The \\ Netherlands, ${ }^{3}$ Laboratory of Neurobiology, Institute of Neuroscience, University of Paris IV, 75252 Paris, France, \\ ${ }^{4}$ Department of Cell Biology, Ohio State University, Columbus, Ohio 43210, and ${ }^{5}$ Department of Anatomy, Neuroscience \\ Institute, Erasmus University Rotterdam, 3000 DR Rotterdam, The Netherlands
}

A longstanding but still controversial hypothesis is that longterm depression (LTD) of parallel fiber-Purkinje cell synapses in the cerebellum embodies part of the neuronal information storage required for associative motor learning. Transgenic mice in which LTD is blocked by Purkinje cell-specific inhibition of protein kinase $\mathrm{C}$ (PKC) (L7-PKCl mutants) do indeed show impaired adaptation of their vestibulo-ocular reflex, whereas the dynamics of their eye movement performance are unaffected. However, because L7-PKCI mutants have a persistent multiple climbing fiber innervation at least until $35 \mathrm{~d}$ of age and because the baseline discharge of the Purkinje cells in the L7-PKCl mutants is unknown, factors other than a blockage of LTD induction itself may underlie their impaired motor learning. We therefore investigated the spontaneous discharge of Purkinje cells in alert adult L7-PKCl mice as well as their multiple climbing fiber innervation beyond the age of 3 months. We found that the simple spike and complex spike-firing properties (such as mean firing rate, interspike interval, and spike count variability), oscillations, and climbing fiber pause in the L7-PKCI mutants were indistinguishable from those in their wild-type littermates. In addition, we found that multiple climbing fiber innervation does not occur in cerebellar slices obtained from 3to 6-month-old mutants. These data indicate (1) that neither PKC inhibition nor the subsequent blockage of LTD induction disturbs the spontaneous discharge of Purkinje cells in alert mice, (2) that Purkinje cell-specific inhibition of PKC detains rather than prevents the developmental conversion from multiple to mono-innervation of Purkinje cells by climbing fibers, and (3) that as a consequence the impaired motor learning as observed in older adult L7-PKCl mutants cannot be attributable either to a disturbance in the baseline simple spike and complex spike activities of their Purkinje cells or to a persistent multiple climbing fiber innervation. We conclude that cerebellar LTD is probably one of the major mechanisms underlying motor learning, but that deficits in LTD induction and motor learning as observed in the L7-PKCl mutants may only be reflected in differences of the Purkinje cell signals during and/or directly after training.

Key words: heterosynaptic plasticity; motor learning; multiple climbing fiber innervation; cerebellar and vestibular nuclei; genetic manipulation; phosphorylation
A challenge faced by neuroscience is to understand how model systems of information storage in the brain, such as long-term potentiation and long-term depression (LTD), function in neural circuits that control behavioral learning. Cerebellar LTD is an attenuation of the granule cell axon-Purkinje cell synapse that occurs after conjunctive stimulation of the granule cell axons and climbing fiber inputs (Ito et al., 1982; Linden and Connor, 1995). It has been suggested that LTD underlies several forms of motor

Received Nov. 27, 2000; revised May 8, 2001; accepted May 18, 2001.

This research was supported by the Life Sciences Foundation [Nederlandse Organisatie voor Wetenschappelijk Onderzoek (NWO) Aard en Levenswetenschappen/Stichting Levenswetenschappen; project no. 805.33.313] (J.G., C.I.D.Z.) subsidized by The NWO, NWO-Medische Wetenschappen (C.I.D.Z., M.A.F., J.v.d.S.), the Erasmus University Rotterdam (C.I.D.Z., M.A.F., J.v.d.S.), the University of Nijmegen (J.G.), the University of Paris (H.D., A.R., F.C.), the Human Frontier Science Program (C.I.D.Z., J.O.), and the Ohio State University (J.O.). We thank B. Weijer, J. van den Burg, and M. M. Morpurgo for technical assistance.

Correspondence should be addressed to Christiaan I. De Zeeuw, Department of Anatomy, Neuroscience Institute, Erasmus University Rotterdam, Dr. Molewaterplein 50, P.O. Box 1738, 3000 DR Rotterdam, The Netherlands. E-mail: DeZeeuw@anat.fgg.eur.nl.

Copyright (C) 2001 Society for Neuroscience $0270-6474 / 01 / 215813-11 \$ 15.00 / 0$ learning, including adaptation of the vestibulo-ocular reflex (VOR) and eye blink conditioning (Ito, 1989).

Several studies using knock-out mice have supported this claim by showing correlations between deficits in LTD and behavioral learning (Aiba et al., 1994; Conquet et al., 1994; Funabiki et al., 1995; Kashiwabuchi et al., 1995; Shibuki et al., 1996). However, the lack of anatomical specificity and functional compensation via similar gene family members has complicated the analyses of knock-out mice. For example, global knock-outs of the type I metabotropic glutamate receptor (mGluR1) show a blockade of LTD induction and impaired eye blink conditioning (Aiba et al., 1994; Conquet et al., 1994), but because this receptor is expressed at multiple sites in the brain, it is difficult to correlate the physiological and behavioral phenotype of the cell (cf. Ichise et al., 2000). To overcome these limitations, we have created a transgenic mouse in which a protein kinase $\mathrm{C}$ (PKC) inhibitory peptide, PKC[19-31], is selectively expressed in Purkinje cells (De Zeeuw et al., 1998). Cultured Purkinje cells from these L7-PKCI mice show a complete blockade of LTD induction, and behavioral analysis indicates a loss of VOR adaptation, whereas the default 
eye movement performance is unaffected. These data support the idea that PKC activation is necessary for LTD induction and that cerebellar LTD is required for plasticity of the VOR.

However, it is currently unknown whether PKC inhibition inside Purkinje cells directly corrupts their signals, which in turn could disturb the learning process. If so, the impaired motor learning in L7-PKCI mutants may not necessarily reflect a lack of LTD. Perhaps LTD itself is essential for a normal operation of the cerebellar circuitry without being involved in memory formation at all. As proposed by De Schutter (1995), LTD might instead normalize Purkinje cell excitation as a protective mechanism.

It is not unlikely that L7-PKCI Purkinje cells show abnormal firing properties, because some of their kinase-regulated ion channels may control interspike intervals (ISIs) (Nelson et al., 1996) and some of their kinase-regulated proteins involved in calcium metabolism, such as calretinin, can influence both simple spike and complex spike firing (Schiffmann et al., 1999). Moreover, inhibition of PKC could result in multiple climbing fiber innervation, which has been observed in adult global PKC $\gamma$ knock-outs (Kano et al., 1995) and in L7-PKCI transgenics up to 35 d of age (De Zeeuw et al., 1998).

Thus, if the baseline discharge properties of Purkinje cells are abnormal, there are ample reasons to believe that the impaired adaptation of L7-PKCI mutants results from side effects rather than from a lack of LTD as a mechanism of plasticity (see also Lisberger, 1998). We therefore examined the spontaneous activity of Purkinje cells in alert L7-PKCI mice as well as the persistence of their multiple climbing fiber innervation beyond the age of 3 months.

\section{MATERIALS AND METHODS}

Mice

We used heterozygous transgenic L7-PKCI mice and their wild-type littermates. In the L7-PKCI mouse, the pseudosubstrate PKC inhibitor, PKC[19-31], is selectively expressed in Purkinje cells under the control of the pcp-2(L7) gene promotor (De Zeeuw et al., 1998). All animals were bred in a C57BL/6 mouse strain background. Wild-type and mutant mice were treated equally as far as housing and experimental conditions were concerned.

\section{Electrophysiology in alert animals}

Surgery. Mice, 3- to 12-months old, were prepared for chronic neurophysiological experiments under inhalant anesthesia with $\mathrm{N}_{2} \mathrm{O} / \mathrm{O}_{2}$ and halothane $(1.5-2 \%)$. First, a head holder was tightly fixed to the skull by embedding two nuts and four bone screws in dental cement, which allowed for rigid head restraint during the experiments. Second, a small hole $(\cong 3 \mathrm{~mm}$ ) was drilled in the left occipital bone, and the exposed dura was partly removed with great care. Subsequently, dental cement was molded around the hole to form a recording chamber, which was then closed using bone wax. After surgery, the animals were allowed to recover for $1-2 \mathrm{~d}$ before the recording sessions.

In vivo recordings. Extracellular activity was recorded in the cerebellar vermis and paramedian lobule using glass micropipettes filled with $2 \mathrm{M}$ $\mathrm{NaCl}$ (tip diameter $\sim 2-5 \mu \mathrm{m}$; impedance $\sim 2.5 \mathrm{M} \Omega$ at $1 \mathrm{kHz}$ ). The electrode tip was positioned on the cerebellar surface under visual guidance (Olympus VS-IV; Olympus Optical, Tokyo, Japan) using a micromanipulator (David Kopf Instruments, Tujunga, CA) and moved downward by a hydraulic microdrive (Trent Wells) equipped with a stepping motor (TL Elektronik SMS 87). The electrode signal was amplified and filtered (bandwidth 10-6000 Hz; Dagan 2400; Dagan, Minneapolis, MN) and was sampled at $12.5 \mathrm{kHz}$ (CED 1401plus, Spike2, Cambridge, UK). Single-unit Purkinje cells were identified on-line by the presence of a brief pause in simple spikes after the complex spike (see Fig. 1 for representative examples). In the off-line analysis, simple spikes and complex spikes were detected and discriminated using custom software implemented in Matlab (version 5.2-5.3; Mathworks, Natick, MA), which clustered groups of spikes by amplitude, duration, and shape using
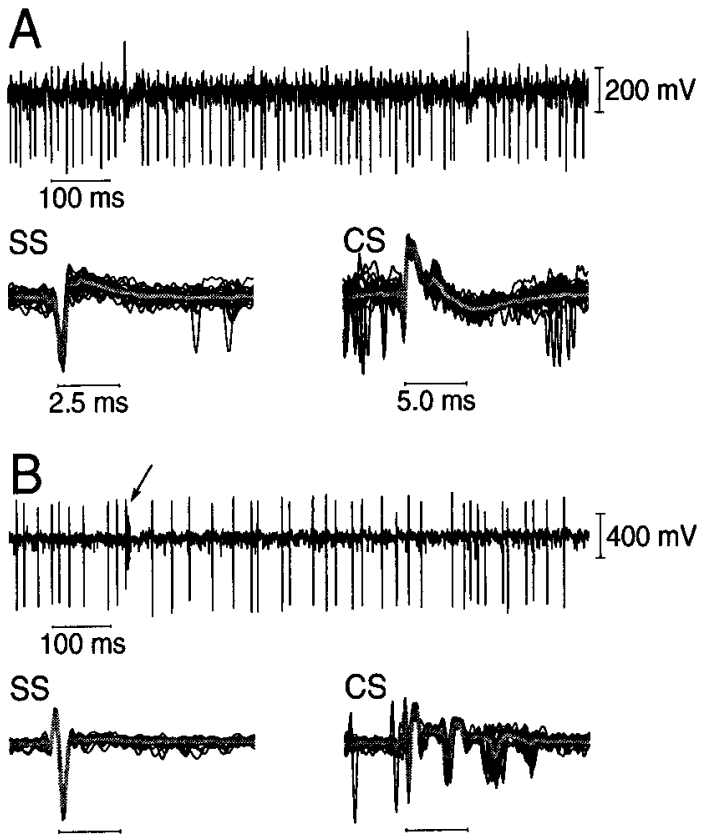

$\overrightarrow{2.5 \mathrm{~ms}}$

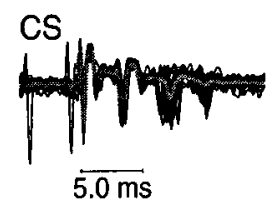

Figure 1. Representative extracellular single-unit recordings from two Purkinje cells in the alert mouse. Top traces in $A$ and $B$ show $1 \mathrm{sec}$ of raw electrode signal, sampled at $12.5 \mathrm{kHz}$ after amplification and band-pass filtering (see Materials and Methods). Bottom traces depict the simple spike $(S S)$ and complex spike $(C S)$ waveforms at higher temporal resolutions ( 25 events with the mean superimposed). Note that the complex spikes in $A$ are easily identified in the raw signal by their large positive component, but in $B$, the complex spike (arrow) cannot be discriminated from the simple spikes by polarity. However, the waveform analysis procedure (see Materials and Methods) enabled reliable discrimination of simple spikes and complex spikes in both examples as well as in all other, more intermediate cases.

a linear discriminant analysis on the first four principal components of the spike wave forms (Eggermont, 1990).

Spike train analysis. ISI histograms, $I(t)$, were derived from 2- to 5-min recording epochs of spontaneous simple spike and complex spike activity (bin widths of $\Delta t=0.5$ and $\Delta t=50 \mathrm{msec}$, respectively). The mean and variance $\left(\mu_{t}\right.$ and $\left.\sigma_{t}^{2}\right)$ of the simple spike and complex spike ISIs as well as mean firing rates $\left(f=1 / \mu_{t}\right)$ and coefficients of variation $\left(C_{V}=\sigma_{t} / \mu_{t}\right)$ were computed using standard methods (Gabbiani and Koch, 1998). The most likely ISI $\left(\lambda_{t}\right)$ was derived from the peak of the ISI histogram.

The long-term dynamics (seconds to minutes domain) of both simple spike and complex spike firing were evaluated using the index of dispersion or Fano factor, $F(T)$, which is the ratio of the spike count variance, $V(T)$, to the mean spike count, $N(T)$, in a certain counting window $T$ $[F(T)=V(T) / N(T)]$ (Gabbiani and Koch, 1998). Estimates of $N(T)$ and $V(T)$ were obtained by subdividing a spike train into partly overlapping intervals of duration $T$, and the counting time was systematically varied. $F(T)$ was evaluated by plotting $V(T)$ versus $N(T)$ in double-log coordinates, and linear regression lines, $X=\alpha Y+\beta$ [with $X=\log N(T)$ and $Y=\log V(T)]$, were fitted to the resulting curves for $N(T)>1$. If spiking can be described as a renewal process (that is, if the ISIs are independently and identically distributed), the data would fall on a straight line with slope $\alpha=1$ and bias $\beta=2 \log C_{V}$ because under these conditions $V(T) \cong C_{V}^{2} \cdot N(T)$ [except for short $T$ because $F(T)$ converges to 1 for $T \rightarrow 0]$ (Cox, 1962).

Simple spike activity was inspected for the presence of oscillations using autocorrelation histograms $[r(\tau)$ in spikes per second; bin width $\Delta t=1.0 \mathrm{msec}$; lag time $-300 \leq \tau \leq 300 \mathrm{msec}]$. The degree of simple spike rhythmicity was quantified by a rhythm index $(R I)$, calculated in a manner similar to Lang et al. (1997):

$$
R I=\sum_{i=1}^{n_{p}}\left|c\left(\tau_{p, i}\right)\right|+\sum_{j=1}^{n_{v}}\left|c\left(\tau_{v, j}\right)\right|,
$$


in which $c\left(\tau_{p, i}\right)$ and $c\left(\tau_{v, j}\right)$ are the autocorrelation coefficients at lag times $\tau_{p, i}$ and $\tau_{v, j}$ corresponding to the $i$ th peak $\left(i=1,2, \cdots, n_{p}\right)$ and $j$ th valley $\left(j=1,2, \cdots, n_{v}\right)$, respectively. Autocorrelation coefficients were calculated from the conditional firing rate, $r(\tau)$, using the following equation:

$$
c(\tau)=\frac{r(\tau)-b}{\Delta t^{-1}-b},
$$

in which $b$ is the baseline firing rate given by $b=N_{\text {tot }} / T_{\text {rec }}\left(N_{\text {tot }}\right.$ is the total number of spikes and $T_{r e c}$ is the total recording time) and $\Delta t$ is the bin width of the histogram. Only successive peaks and valleys that deviated more than $\pm 2 \mathrm{SD}$ from the baseline were included. The SD of activity about the baseline was measured at time lags of 250-300 msec, which modulation of the conditional firing rate was absent. The oscillation period, $\mathrm{T}_{o s c}$, was calculated from the following equation:

$$
\mathrm{T}_{\text {osc }}=\sum_{i=1}^{n_{p}} \frac{\tau_{p, i}}{i\left(n_{p}+n_{v}\right)}+\sum_{j=1}^{n_{v}} \frac{\tau_{v, j}}{(j+0.5)\left(n_{p}+n_{v}\right)} .
$$

Oscillatory frequency was given by $f_{\text {osc }}=1 / \mathrm{T}_{\text {osc }}$. To examine whether the oscillatory patterns could be understood from the regularity of the ISIs (see Results), renewal density histograms $\left[R^{+}(\tau)\right.$; lag time, $0<\tau \leq 300$ $\mathrm{msec}]$ were computed from the (first order) ISI histograms, $I(\tau)$, according to the following equation:

$$
R^{+}(\tau)=\left[I(\tau)+\sum_{k=1}^{\infty} I^{(k)}(\tau)\right] / \Delta t,
$$

in which $I^{(k)}(\tau)$ denotes the result of a $k$-fold convolution of $I(\tau)$, thus representing the second- and higher-order ISI distributions, $I_{k+1}(\tau)$, formed by joining adjacent ISIs (Eggermont, 1990). $\Delta t$ is the bin width of $I(\tau)$. An alternative procedure for obtaining these histograms is to compute averaged autocorrelation histograms from spike trains with randomly shuffled ISIs (Mountcastle et al., 1969).

Cross-correlation histograms of simple spikes and complex spikes (in spikes per second; bin width, $\Delta t=1.0 \mathrm{msec}$; lag time, $-300 \leq \tau \leq 300$ $\mathrm{msec}$ ) were used to quantify the climbing fiber pause (CFP) (Simpson et al., 1996). In addition, ISI histograms of the interval between a complex spike and the first following simple spike were made (bin width, $\Delta t=1.0$ msec) to evaluate the complex spike-simple spike interval (CSI) statistics.

\section{Electrophysiological and fluorescence measurements in cerebellar slices}

Slice preparation. Sagittal slices (250-300 $\mu$ m thick) were prepared from the cerebellar vermis as described previously (Conquet et al., 1994). Cerebellar LTD and the climbing fiber innervation of Purkinje cells were tested in slices prepared from mice of 3 weeks to 6 months of age. Slices were incubated at room temperature in saline solution gassed with $95 \%$ $\mathrm{O}_{2} / 5 \% \mathrm{CO}_{2}$ for at least $2 \mathrm{~h}$ before recording. During experiments, the recording chamber was continuously perfused at a rate of $2 \mathrm{ml} / \mathrm{min}$ with oxygenated saline solution of the following composition (in $\mathrm{mM}$ ): 124 $\mathrm{NaCl}, 3 \mathrm{KCl}, 24 \mathrm{NaHCO}_{3}, 1.15 \mathrm{KH}_{2} \mathrm{PO}_{4}, 1.15 \mathrm{MgSO}_{4}, 2 \mathrm{CaCl}_{2}, 10$ glucose, and the $\mathrm{GABA}_{\mathrm{A}}$ antagonist bicuculline methiodide $(10 \mu \mathrm{M}$; Sigma, St. Louis, MO), final $\mathrm{pH}$ of 7.35 at $28^{\circ} \mathrm{C}, 330 \mathrm{mOsm} / 1$. Recordings of Purkinje cells under visual control were performed at the somatic level, using the whole-cell patch-clamp technique with an Axopatch 1D or an Axopatch 200 amplifier (Axon Instruments, Foster City, CA). For pairing experiments, synaptic activation of metabotropic glutamate receptor experiments, and kinetic measurements in climbing fiber innervation experiments (see Results), access resistance was partially (50$70 \%$ ) compensated according to the procedure described by Llano et al. (1991). For analysis, electrophysiological data were filtered at $2 \mathrm{kHz}$ and digitized at $20 \mathrm{kHz}$. Climbing fiber and parallel fiber-mediated responses were analyzed on-line and off-line using the Acquis1 computer program (Biologic, Grenoble, France).

Pairing experiments. In pairing experiments, the patch pipettes (2-3.5 $\mathrm{M} \Omega$ ) were filled with an internal solution containing (in mM): $140 \mathrm{KCl}$, $8 \mathrm{NaCl}, 10$ HEPES, 2 ATP-Mg, 0.75 EGTA, final $\mathrm{pH}$ of 7.3 with $\mathrm{KOH}$, $300 \mathrm{mOsmol} / 1$. Cells were maintained at a holding potential of $-70 \mathrm{mV}$ and, as reported previously (Crépel and Jaillard, 1991), parallel fibers were stimulated at $0.33 \mathrm{~Hz}$ through a monopolar electrode placed at the surface of the slice, in the lower half of the molecular layer at the level of the proximal dendrites of the recorded cells. Throughout the record- ing, parallel fiber-mediated EPSCs were elicited on a $10 \mathrm{mV}$ hyperpolarizing voltage step that allowed testing of the passive properties of the recorded cells as well as the stability of access resistances. In these experiments, parallel fiber-mediated EPSCs were first evoked in Purkinje cells during a control period of at least 5 min to obtain baseline data. Next, two successive pairing protocols separated by $5 \mathrm{~min}$ were performed in an attempt to saturate LTD. For each of these pairings, the recording mode was changed to current clamp for $1 \mathrm{~min}$, and parallel fiber-mediated EPSPs were evoked at $1 \mathrm{~Hz}$ during this period, in conjunction with $\mathrm{Ca}^{2+}$ spikes elicited in Purkinje cells by both a steady depolarizing current passed through the recording electrode and depolarizing steps timed to coincide with parallel fiber stimulation. The voltage-clamp mode and the initial frequency of stimulation were resumed just after the end of the pairing protocol.

Synaptic activation of metabotropic glutamate receptor experiments. In these experiments, the patch pipettes $(2-3 \mathrm{M} \Omega$ ) were filled with a solution containing (in mM): $140 \mathrm{CsCl}, 8 \mathrm{NaCl}, 10$ HEPES, $2 \mathrm{ATP}-\mathrm{Mg}$, 0.5 EGTA, pH of 7.3 with $\mathrm{CsOH}, 300 \mathrm{mOsm} / 1$. To obtain synaptically induced metabotropic glutamate receptor responses, Purkinje cells were voltage clamped at $-70 \mathrm{mV}$ and recorded in the presence of bicuculline methiodide $\left(10 \mu \mathrm{M}\right.$; Sigma) to block $\mathrm{GABA}_{\mathrm{A}}$ receptors and in the presence of AP-5, (50 $\mu \mathrm{M}$; Tocris) and 6-cyano-7-nitroquinoxaline-2,3dione (CNQX) $(20 \mu \mathrm{M}$; Tocris Cookson, Bristol, UK) to block ionotropic glutamate receptors (Batchelor and Garthwaite, 1997; Tempia et al., 1998). As established previously (Tempia et al., 1998), a brief train of stimulation pulses was delivered at $100 \mathrm{~Hz}$ through a monopolar electrode in the molecular-to-parallel fibers layer to induce postsynaptic currents mediated by metabotropic glutamate receptors.

Climbing fiber innervation experiments. In the climbing fiber innervation experiments, the EGTA concentration was raised to $5 \mathrm{~mm}$, and 0.5 $\mathrm{mm} \mathrm{CaCl}{ }_{2}$ was added to the internal solution that was used in pairing experiments. Moreover, $2 \mathrm{~mm} \mathrm{~N}$-2,6-dimethylphenylcarbamoylmethyl triethylammonium bromide (Alomone Labs, Jerusalem, Israel) was added to block sodium spikes. Purkinje cells were maintained at -80 $\mathrm{mV}$. Climbing fibers were stimulated at $0.33 \mathrm{~Hz}$ through a monopolar electrode placed at the surface of the slice, near the soma of the recorded cell. For each cell, several locations of the stimulating electrode in the internal granular layer and in the lower half of the molecular layer were tested for their ability to evoke potential multistep climbing fiber-mediated EPSCs. Throughout the recording, climbing fiber-mediated EPSCs were elicited on a $10 \mathrm{mV}$ hyperpolarizing voltage step that allowed monitoring of the passive electrical properties of the recorded cell.

Fluorescence measurements. As described previously (Daniel et al, 1999), fluorescence measurements with the dye fluo3, a high-affinity $\mathrm{Ca}^{2+}$ indicator, were performed to detect changes in intracellular free calcium into the Purkinje cell dendrites. Fluo3-free acid $(100 \mu \mathrm{M})$ added to the internal medium was introduced into the cell via the patch pipette. The recording session started 30-45 min after whole-cell "break in," to allow dye diffusion in the dendrites and to wash out the background fluorescence in surrounding tissue that occurs because of leakage of the dye from the pipette just before the formation of the seal. The $\mathrm{Ca}^{2+}$ sensitive dye was excited by light from a $100 \mathrm{~W}$ xenon lamp, and the epifluorescence excitation wavelength was at $485 \pm 22 \mathrm{~nm}$. The emitted light was collected by a photometer through a barrier filter at $530 \pm 30$ $\mathrm{nm}$, from an area $(15 \times 15 \mu \mathrm{m})$ centered on proximal dendrites. Because this single wavelength method does not determine absolute free $\mathrm{Ca}^{2+}$ levels, the fluorescence changes in fluo 3 were expressed as a ratio with respect to the initial background-corrected resting fluorescence. Fluorescence data were analyzed on-line and off-line by using Acquis 1 computer software (Biologic).

\section{Statistics}

Statistical evaluation of the data included Student's $t$ tests, KolmogorovSmirnov tests (KS tests), and a $\chi^{2}$ test (Press et al., 1992). Significance levels are indicated in Results.

\section{RESULTS}

\section{Spontaneous Purkinje cell activity in alert L7-PKCI mutants}

We recorded spontaneous Purkinje cell activity in the cerebellar vermis and paramedian lobule of alert LTD-deficient L7PKCI $+/-$ mice $(n=10)$ and their wild-type littermates (L7- 
Figure 2. Purkinje cells in alert wildtype and L7-PKCI mutant mice show similar mean firing rates and coefficients of variation. $A$, Interspike interval histograms of simple spike $(S S)$ and complex spike $(C S)$ activity of a wildtype (L7-PKCI-/-) Purkinje cell. Mean firing rates, $f_{s s}=78$ spikes $/ \mathrm{sec}$ and $f_{c s}=1.2 \mathrm{spikes} / \mathrm{sec}$. Coefficients of variation, $C_{V_{s s}}=0.39$ and $C_{V c s}=0.81$. Bin width is $0.5 \mathrm{msec}$ in $A_{1}$ and 50 msec in $A_{2}$. $B$, Interspike interval histograms of a mutant (L7-PKCI $+/-)$ Purkinje cell. Mean firing rates, $f_{s s}=$ $58 \mathrm{spikes} / \mathrm{sec}$ and $f_{c s}=1.2 \mathrm{spikes} / \mathrm{sec}$. Coefficients of variation, $C_{V s s}=0.64$ and $C_{V c s}=1.09 . C, D$, Population average of the mean simple spike rates (C) and the mean complex spike rates $(D)$ in wild-type and mutant Purkinje cells. Error bars indicate $1 \mathrm{SD}$. Mean \pm SD in wild types $(n=44)$ $\left(f_{s s}=59 \pm 26\right.$ spikes $/ \mathrm{sec}$ and $f_{c s}=$ $0.9 \pm 0.4$ spikes $/ \mathrm{sec}$ ) and in mutants $(n=51)\left(f_{s s}=58 \pm 21\right.$ spikes $/ \mathrm{sec}$ and $f_{c s}=1.0 \pm 0.4$ spikes $\left./ \mathrm{sec}\right)$. Neither simple spike nor complex spike firing rates are significantly different. $E$, Scatter plot of simple spike versus complex spike mean firing rates for wild-type and mutant Purkinje cells. Note the considerable yet very similar cell-tocell variability in wild-type $(\bigcirc)$ and mutant $(-$ mice. $F$, Scatter plot of simple spike versus complex spike coefficients of variation for both cell populations. Typically, $C_{V_{s s}}$ and $C_{V c s}$ are $<1$, and the distributions largely overlap. Mean $\pm \mathrm{SD}$ in wild types, $C_{V s s}=0.7 \pm 0.4$ and $C_{V c s}=0.9 \pm 0.2$; in mutants, $C_{V s s}=0.7 \pm 0.3$ and $C_{V c s}=0.9 \pm 0.2$.
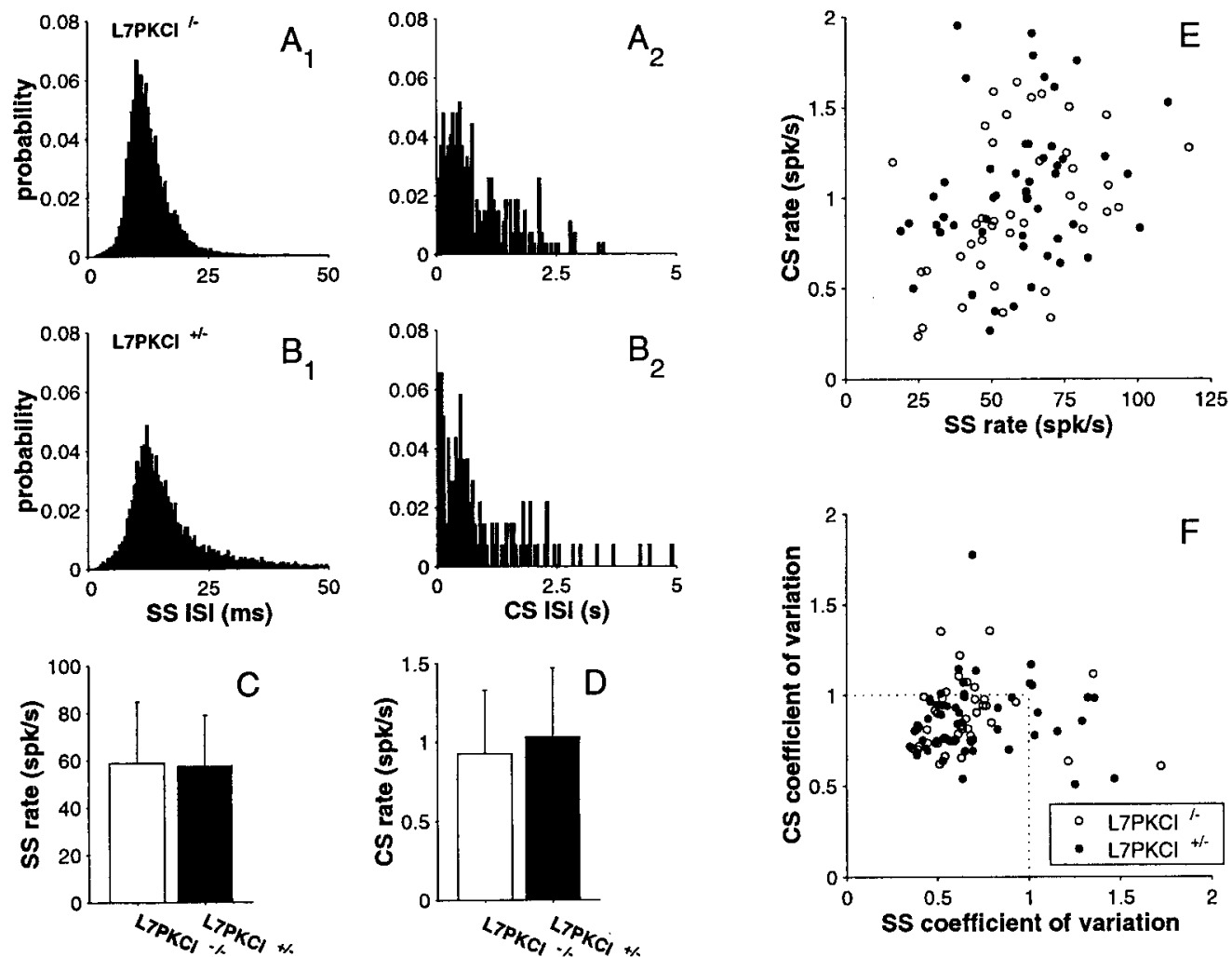

PKCI $-/-; n=12)$. Cells were selected for recording once they were well isolated (Fig. 1). Histograms of simple spike activity triggered on the occurrence of a complex spike were made to verify that each Purkinje cell showed a clean climbing fiber pause (Simpson et al., 1996) (see below for quantitative data). In this manner, simultaneous records of simple spikes and complex spikes were obtained from 95 single-unit Purkinje cells (44 wild types and 51 mutants).

\section{Interspike intervals}

To examine whether inhibition of various PKC isoforms and/or the consequent blockage of LTD induction affected the shortterm stochastics of Purkinje cell firing, we plotted ISI histograms. Figure 2 shows the simple spike and complex spike ISI histograms obtained from a wild-type (L7-PKCI-/-) (Fig. $2 A_{1}, A_{2}$ ) and a mutant Purkinje cell (L7-PKCI+/-) (Fig. $2 B_{1}, B_{2}$ ). The mean firing rate, $f$, and the coefficient of variation, $C_{V}$, of the simple spike and complex spike discharge were quantified for each cell. Figure 2, $C$ and $D$, shows comparisons of the population averages of the mean simple spike and mean complex spike rates for the two genotypes. Note that the average values of the simple spike rates in $\mathrm{L} 7-\mathrm{PKCI}+/-$ and $\mathrm{L} 7-\mathrm{PKCI}-/-$ mice are not significantly different $\left(f_{s s} \cong 60\right.$ spikes/sec for both genotypes; Student's $t$ test; $p=0.8$ ) (Fig. $2 C$ ). The average values of the complex spike rates are also very similar for the two genotypes $\left(\overline{f_{c s}} \cong 1.0\right.$ spikes $/ \mathrm{sec}$ in both cases; Student's $t$ test; $p=0.3$ ) (Fig. 2D). It should be noted, however, that there is considerable cell-to-cell variability in the mean firing rates and that this variability rather than the population average might be different in the two genotypes. To overcome this potential pitfall, we also compared the distributions of mean firing rates. It turned out, however, that the distribution of both simple spike rates and complex spike rates is indistinguishable (KS test; $p>0.6$ ). Even when the mean complex spike rate of individual Purkinje cells is plotted against their mean simple spike rate (Fig. 2E, scatter plot), it is observed that the twodimensional (2D) distribution of the PKCI $-/-$ data (Fig. 2E, $\bigcirc$ ) overlaps the distribution of the $\mathrm{PKCI}+/-$ data (Fig. $2 E, \mathbf{O}$ ), indicating that there is no significant difference (2D KS test; $p=$ 0.7). Similar results were obtained with regard to the temporal jitter in simple spikes and complex spikes, as quantified by the $C_{V}$. This is shown in the scatter plot of Figure $2 F$, in which the complex spike coefficient of variation is plotted versus the simple spike coefficient of variation for wild-type (Fig. $2 F, \bigcirc$ ) and mutant (Fig. $2 F, 0$ ) Purkinje cells. Note that the simple spike coefficient of variation was $<1$ for the vast majority of cells, indicating that the simple spike ISI distributions are typically more regular than the distributions associated with a pure Poisson process (for which $C_{V}$ equals 1 ). The complex spike coefficients of variation were also $<1$ for most wild-type and mutant neurons, but the average values were closer to unity than the ones obtained for simple spike firing $\left(\overline{C_{V c s}} \cong 0.9\right.$ versus $\overline{C_{V_{s s}}} \cong 0.7 \mathrm{in}$ both genotypes). Only a limited fraction of the cells showed a burst-like simple spike and/or complex spike discharge, resulting in coefficients of variation substantially greater than 1 . The distribution of complex spike versus simple spike coefficients of variation was not significantly different for the two genotypes (2D $\mathrm{KS}$ test; $p=0.4)$.

\section{Spike count variability}

In subsequent analyses, we evaluated spike count variability [quantified by the Fano factor, $F(T)$ ] to examine possible differences in the long-term discharge dynamics (see Materials and 

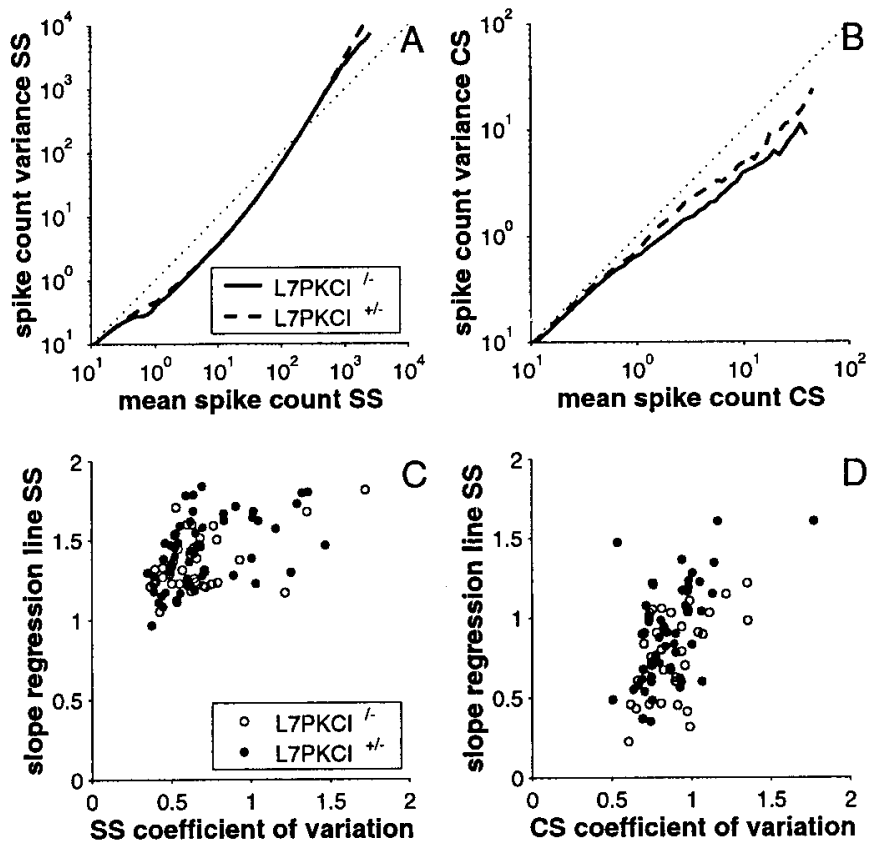

Figure 3. Spike count variability is similar in Purkinje cells of alert wild-type and L7-PKCI mutant mice. $A, B$, Spike count variance as a function of the mean for simple spike $(S S)(A)$ and complex spike $(C S)$ $(B)$ activity of a wild-type (L7-PKCI-/-) and a mutant (L7-PKCI+/-) Purkinje cell. Note that the curves are approximately linear for $N(T)>1$ (corresponding to counting times that exceed the mean ISI duration). Slopes of the linear regression lines fitted to these data were $\sim 1.3$ in $A$ and $\sim 0.8$ in $B$. The identity line corresponds to the Fano factor for a Poisson process (for which $F(T)=1$ ). Note the scaling differences between $A$ and $B$. $C, D$, Scatter plots of the regression-line slope versus the coefficient of variation for simple spike $(C)$ and complex spike $(D)$ activity in wild-type $(\bigcirc)$ and mutant $(\bullet)$ Purkinje cells. Slopes $>1$ imply long-term correlations in the data. Slopes obtained for simple spike activity exceed unity in virtually all Purkinje cells (mean $\pm \mathrm{SD}, \alpha_{s s}=1.4 \pm 0.2$ in both genotypes; Pearson's correlation coefficients, 0.988-0.999). Slopes obtained for complex spike activity are related to the complex spike coefficient of variation and range between 0.22 and 0.61 variation (mean $\pm \mathrm{SD}, \alpha_{c S}=0.8 \pm 0.3$ in wild types and $\alpha_{c s}=0.9 \pm 0.3$ in mutants; Pearson's correlation coefficients, 0.819-0.999).

Methods). For counting windows on the order of one to five times the mean ISI, corresponding to mean spike counts of approximately one to five spikes, $F(T)$ was typically approximately equal to the corresponding $C_{V}{ }^{2}$, as expected for a renewal process. For longer integration times, however, the Fano factor evolved differently for both simple spike and complex spike firing. This is illustrated in Figure 3, $A$ and $B$, which depicts the variance versus mean spike count curves in double-log coordinates for simple spike (Fig. 3A) and complex spike (Fig. 3B) firing of a wild-type and a mutant Purkinje cell. Note that the curves are approximately linear for mean spike counts $>1$, but the variance in the number of simple spike events grows faster than the mean (Fig. $3 A$ ), indicating long-term correlations in the simple spike data. Temporal order in the simple spike sequences was also evident from plots of serial correlation coefficients, which showed positive correlations between contiguous and noncontiguous ISIs (data not shown). In contrast, the curves for complex spike variability exhibit slopes that are less than unity (Fig. $3 B$ ), suggesting that some regularity is imposed. The scatter plots in Figure 3, $C$ and $D$, summarize the results of this analysis for all cells. Note that for simple spike dispersion, the slopes of the regression lines exceed unity in nearly all Purkinje cells (range 0.96-1.84). Thus, regard- less of the coefficient of variation, a substantial proportion of the simple spike variability is not explained by interspike interval variability. For complex spike dispersion, slopes ranged between 0.22 and 1.61, and they depended on the complex spike coefficient of variation. There were no significant differences between the two cell populations (KS test; $p>0.2$ ), indicating that the long-term dynamics of simple spike and complex spike firings are very similar in wild-type and mutant mice.

\section{Simple spike oscillations}

Autocorrelation histograms indicated the presence of highfrequency oscillations in the simple spike discharge of most Purkinje cells (>95\%). Figure 4, $A$ and $B$, shows the autocorrelation histogram of simple spike activity in two wild-type and two mutant Purkinje cells, respectively. Note that the conditional firing rates in Figure $4, A_{1}$ and $B_{1}$, peak at approximately \pm 11 msec, whereas peaks occur at approximately $\pm 14, \pm 28$, and \pm 42 msec in Figure $4, A_{2}$ and $B_{2}$. For the vast majority of wild-type and mutant Purkinje cells, these findings reflected the regularity of the ISI distribution (compare Fig. $2, A_{1}$ and $B_{1}$, for the ISI histograms of the two cells in Fig. 4, $A_{1}$ and $B_{1}$ ). This is illustrated in Figure $4, A_{1,2}$ and $B_{1,2}$, by superimposing the renewal density histograms, $R^{+}(\tau)$ (solid curves), computed from the corresponding ISI histograms (see Materials and Methods). Note that the predicted oscillatory patterns correspond quite well to the observed ones. As may be inferred from the $R^{+}(\tau)$ equation (see Materials and Methods), these results suggest that the oscillation period, $\mathrm{T}_{\text {osc }}$, will approximately equal the duration of the most likely simple spike ISI, $\lambda_{t}$. After all, for a unimodal, regular ISI distribution, the contribution of the first (dominant) term, $I(\tau)$, tends to produce a peak in $R^{+}(\tau)$ at $\tau \cong \lambda_{t}$, whereas the contribution of each higher-order joint ISI distribution, $I_{k+1}(\tau)$, tends to produce an additional peak at $\tau \cong(k+1) \cdot \lambda_{t}$. The tendency for $I(\tau)$ and $I_{k+1}(\tau)$ to yield significant peaks depends of course on the degree of regularity of $I(\tau)$ and declines as a function of $k$. Figure $4 C$ shows that for the vast majority of cells, the oscillation period does indeed match the duration of the most likely simple spike ISI very closely in both genotypes (Pearson's correlation coefficients, $>0.9$ ). However, as expected from the presence of serial correlations in the ISIs (Fig. 3), the amplitudes of peaks and valleys in the renewal density functions were typically reduced compared with those in the autocorrelation histograms. Figure 4 $D-G$ summarizes the observed oscillatory patterns. Approximately $50 \%$ of the cells showed two or more significant peaks in both cell populations (Fig. $4 D, E$ ), and there was no significant difference between the frequency distribution for the two genotypes ( $\chi^{2}$ test; $p=0.2$ ). A rhythm index, $R I$, (see Materials and Methods) was used to further quantify the strength of the simple spike oscillations. For cells showing at least one peak, rhythm indices ranged between 0.005 and 0.192 in wild-type mice and between 0.004 and 0.399 in mutant mice (Fig. 4, $F$ and $G$, respectively), but their distributions were not significantly different (KS test; $p=0.2$ ).

\section{Climbing fiber pause}

As illustrated by the examples in Figure $5, A_{1}$ and $B_{1}$, crosscorrelation histograms of simple spike and complex spike activity indicated a transient pause (complete suppression) of simple spike activity for all isolated Purkinje cells. After this pause (referred to as climbing fiber pause in the literature; Armstrong, 1974), the simple spike activity showed one of three general patterns (McDevitt et al., 1982; Sato et al., 1992; Simpson et al., 
Figure 4. Purkinje cells in alert wild-type and L7-PKCI mutants show comparable simple spike oscillation patterns. $A, B$, Simple spike autocorrelation histograms from two wild-type (L7-PKCI-/-) and two mutant (L7-PKCI+/-) Purkinje cells. Bin width, $1 \mathrm{msec}$. For the two wild-type cells in $A, f_{\text {osc }}=90 \mathrm{~Hz}, R I=0.066\left(A_{1}\right)$ and $f_{\text {osc }}=69 \mathrm{~Hz}, R I=0.121\left(A_{2}\right)$. For the two mutant cells in $B: f_{o s c}=81 \mathrm{~Hz}$, $R I=0.052\left(B_{I}\right)$ and $f_{\text {osc }}=73 \mathrm{~Hz}, R I=$ $0.103\left(B_{2}\right)$. Superimposed are renewal density histograms (solid curves), calculated from the simple spike ISI histograms (see Materials and Methods). Note that these curves resemble the data remarkably well in all four cases. The ISI histograms used to compute the curves in $A_{1}$ and $B_{1}$ are plotted in Figure $2, A_{1}$, and $B_{1}$, respectively (same cell recordings). $C$, Simple spike oscillation period versus the most likely simple spike ISI for wild-type $(\bigcirc)$ and mutant $(\bullet)$ Purkinje cells. Note that the data lie close to the identity line (dotted line). Pearson's correlation coefficients are 0.99 and 0.92 for the L7-PKCI-/- and L7-PKCI+/population, respectively. $D, E$, Frequency distribution of the number of significant peaks in the autocorrelation histograms for the L7-PKCI-/- and L7-PKCI $+/-$ population $(n=44$ and $n=51$, respectively). Note that $\sim 50 \%$

of the cells in both genotypes showed two or more significant peaks. $F, G$, Frequency distribution of rhythm indices for both genotypes. Average $R I$ values for the L7-PKCI-/- and L7-PKCI $+/-$ cell population were $0.06 \pm 0.04$ and $0.09 \pm 0.1$ (mean $\pm \mathrm{SD})$, respectively.

1996): a return to baseline within a few milliseconds (pure pause), a gradual return to baseline over several tens of milliseconds (pause-reduction), and a rapid increase in activity to a level exceeding the baseline for up to several tens of milliseconds (pause-facilitation). Figure $5 C$ quantifies the climbing fiber pause in L7-PKCI-/- and L7-PKCI+/- cells. Note that the average pause duration was approximately $11 \mathrm{msec}$ for both genotypes (Student's $t$ test; $p=0.7$ ). Because the climbing fiber pause reflects only a single event (i.e., the shortest interval occurring between a complex spike and a subsequent simple spike within a recording epoch), we also made histograms of the complex spikesimple spike intervals for each cell (Fig. $5 A_{2}, B_{2}$ ) and quantified the mean and variance of these intervals. As shown in Figure $5 D$, the mean duration of the complex spike-simple spike interval strongly depends on the mean simple spike ISI (Pearson's correlation coefficient, $>0.9)$ in both the PKCI $+/-($ Fig. $5 D, 0)$ and PKCI $-/-($ Fig. $5 D, \bigcirc$ ) cell population (2D KS test; $p=0.2$ ). The mean complex spike-simple spike interval typically exceeds the mean simple spike ISI. This presumably reflects a combination of prolonged refractoriness of the Purkinje cell membrane, climbing fiber-evoked inhibition by basket cells, and reduced excitation by parallel fibers because of the impact of climbing fiber collaterals on Golgi cells, which inhibit the mossy fiber-granule cell pathway (Armstrong, 1974; Simpson et al., 1996). As a result, only part of the variance is explained by the variance in simple spike ISI in most cells (Fig. 5E) (Pearson's correlation coefficient, $>0.8$ ) of both genotypes (2D KS test; $p=0.9$ ). Note, however, that the inhibition of various PKC isoforms and the consequent blockage of LTD induction appear to have no effect on these short-term interactions.

\section{Mono climbing fiber innervation in old L7-PKCI mutants}

Previous slice experiments have indicated that $\sim 50 \%$ of the Purkinje cells in 4- to 5-week-old L7-PKCI animals show a persistent multiple climbing fiber innervation (De Zeeuw et al., 1998). We were surprised therefore that the mean complex spike rate in the Purkinje cells of the alert L7-PKCI mice (3-12 months of age) was normal $\left(\overline{f_{c s}} \cong 1.0\right.$ spikes/sec $)$. More specifically, considering the measured complex spike rates of the wild-type cells (receiving only one climbing fiber), the a priori prediction was to find a significant increase in complex spike rate to $1.4 \pm 0.7$ spikes/sec (mean $\pm \mathrm{SD} ; p<0.001$ ) in the mutants (using Monte Carlo simulation, zaq;/assuming that $50 \%$ of the PKCI $+/-$ cells are excited by two climbing fibers). Clearly, the increase in both mean and SD should have emerged as a change in the distribution of complex spike rates, but this was not the case either (Fig. 2E). Although two distinctly different complex spike waveforms were occasionally identified during spike discrimination, these different complex spikes were never picked up from one and the same Purkinje cell (as inferred from analysis of the climbing fiber pause) and were therefore not included in the analysis. These findings raised the question of whether the multiple climbing fiber innervation found in cerebellar slices of young L7-PKCI animals [postnatal day 28 (P28) to P35] (De Zeeuw et al., 1998) remains evident in mice that are $>3$ months of age, which is the age used for our electrophysiological in vivo recordings.

When slices were prepared from the cerebella of 3- to 6-monthold L7-PKCI mice $(n=10)$ and their wild-type littermates $(n=$ 5 ), no gross differences in morphology were observed at the light 

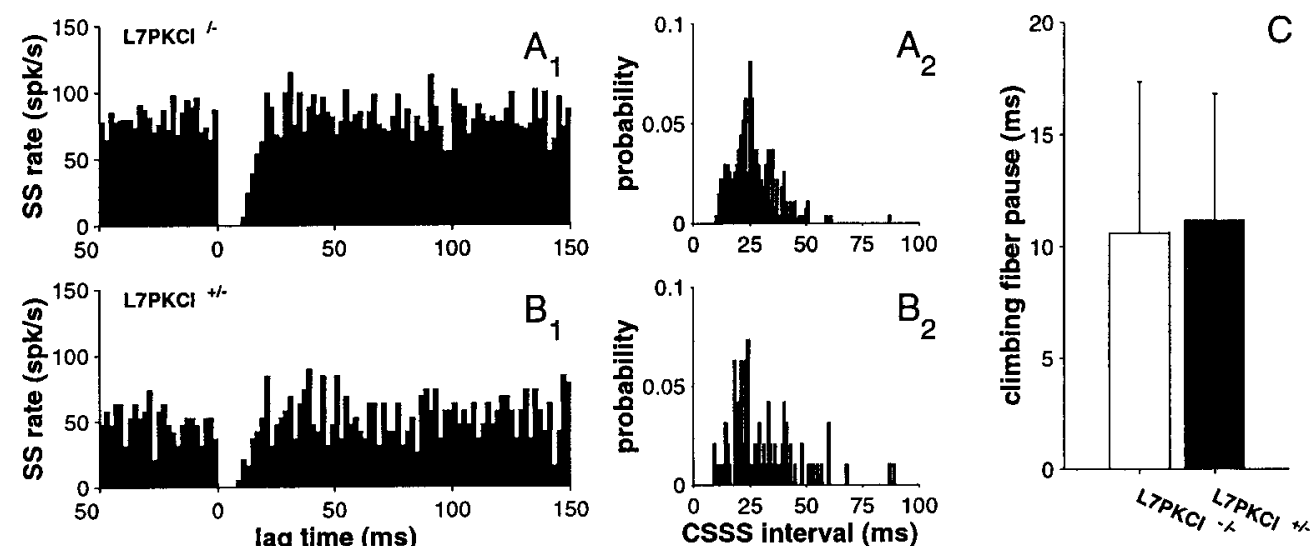

Figure 5. Short-term effect of climbing fiber-mediated complex spikes on simple spike firing is unaltere in L7-PKCI mutants. $A_{1}$, Histogram of simple spikes $(S S)$ triggered by the occurrence of a spontaneous complex spike $(C S)$ for a wild-type Purkinje cell. Bin width, 1 msec CFP in this example, $10 \mathrm{msec} . A_{2}$, Histogram of the interval between a complex spike and the first following simple spike. Bin width, 1 msec. Mean \pm $\mathrm{SD}$ of the distribution, CSI $=21 \pm 10$ msec. $B$, Similar histograms for a mutant Purkinje cell $(\mathrm{CFP}=9 \mathrm{msec}$ and $\mathrm{CSI}=$ $27 \pm 15 \mathrm{msec}$ ). $C$, Average duration of the climbing fiber pause in wild-type and mutant Purkinje cells. Error bars indicate $1 \mathrm{SD}$. Mean $\pm \mathrm{SD}, \mathrm{CFP}=11 \pm$ $7 \mathrm{msec}$ and CFP $=11 \pm 6 \mathrm{msec}$ for L7-PKCI $-/-$ and L7-PKCI+/- cells, respectively. $D$, Mean duration of the complex spike-simple spike intervals correlates well with the mean simple spike ISI $(p<0.0001)$. Pearson's correlation coefficients are 0.93 and 0.92 for the L7-PKCI-/- and L7-PKCI+/cells, respectively. Note the overlap in data for wild type $(\bigcirc)$ and mutants $(\bullet)$, and that most data points lie above the identity line (dotted line). $E$, Variance in the duration of the complex spikesimple spike interval correlates with the variance in simple spike ISIs $(p<$ 0.0001). Pearson's correlation coefficients are 0.84 and 0.87 for the L7PKCI $-/-$ and L7-PKCI $+/-$ cells, re-

spectively, and the data for the two genotypes overlap considerably. Note that the variance of complex spike-simple spike intervals typically exceeds the variance of the simple spike ISIs.

microscopic level (data not shown). Examination of a number of basal electrophysiological parameters also revealed no significant differences between L7-PKCI+/- and L7-PKCI-/- Purkinje cells (Table 1). As shown in Figure 6, multiple climbing fiber innervation was not found in either $\mathrm{L} 7-\mathrm{PKCI}+/-$ or $\mathrm{L7}$ PKCI-/- Purkinje cells. Thus, stimulation of the granular layer or the molecular layer near the recorded Purkinje cell (50-70 $\mu \mathrm{m}$ away) evoked typical all-or-none climbing fiber-mediated EPSCs in the Purkinje cells obtained from slices of L7-PKCI $+/-$ mice (Fig. $6 A 1, A 2)(n=34 ; 10$ cells studied blind) or their wild-type littermates (Fig. $6 B)(n=18 ; 16$ cells studied blind). In the current-clamp mode, these responses recorded at $-70 \mathrm{mV}$ consisted of an initial full spike followed by a plateau of depolarization on which partial spikes were superimposed in both L7PKCI $+-(n=5)$ and L7-PKCI-/ $-(n=5)$ cells (Fig. $6 C)$.

Mean amplitudes, mean rise times, and mean decay time constants of climbing fiber-mediated EPSCs in L7-PKCI mice were not significantly different from those observed in wild-type littermates (Table 1). These parameters were measured in cells with no contamination of climbing fiber-mediated EPSCs by underlying parallel fiber-mediated EPSCs, and the decay time constants of these responses were obtained by fitting the decay phases of EPSCs with single exponentials (Llano et al., 1991). In addition, climbing fiber-mediated EPSCs were unaffected by bath application of the NMDA receptor antagonist AP-5 $(100 \mu \mathrm{M})$ in either L7-PKCI or wild-type mice, but they were blocked by the nonNMDA receptor antagonist CNQX $(10 \mu \mathrm{M})$, indicating that these EPSCs are mediated exclusively by the non-NMDA receptors, as reported previously (Konnerth et al., 1990).

\section{LTD induction is blocked in slices of L7-PKCl mutants}

In vitro experiments have shown that cultured Purkinje cells from L7-PKCI mice show a complete blockage of LTD induction (De Zeeuw et al., 1998). However, the signaling chain underlying cerebellar LTD in cultures may partially differ from that seen in slice preparations (Linden and Connor, 1995; Lev-Ram et al., 1997). For example, presumably because of the absence of sufficient synaptic inputs with the activity of nitric oxide (NO) synthetase in the culture preparation, the role of the NO-PKG pathway in LTD induction can be demonstrated in the slice preparation but not in cultures of Purkinje cells. Therefore, we initiated experiments to investigate whether the general electrophysiological responses of Purkinje cells in cerebellar slices of the L7-PKCI mutants are normal and whether the induction of cerebellar LTD is blocked in these slices.

Stimulation of the parallel fiber parts of the granule cell axons in the molecular layer of L7-PKCI+/- mutants evoked EPSCs that were indistinguishable from those in the wild types; the amplitudes and shapes of their EPSCs equally depended on stimulus intensity. Both responses were totally abolished by bath application of $10 \mu \mathrm{M}$ CNQX, and both were unaffected by $100 \mu \mathrm{M}$ AP-5 (data not shown). In the nine Purkinje cells prepared from six wild-type mice, the pairing protocols of parallel fiber-mediated EPSCs with $\mathrm{Ca}^{2+}$ spikes induced a clear-cut LTD of parallel fiber-mediated EPSCs, which was apparent immediately after the period of pairing and lasted for at least $30 \mathrm{~min}$. The mean amplitude of the parallel fiber-mediated EPSCs was $71.70 \pm 3.41 \%$ of controls (mean $\pm \mathrm{SEM}$ ) $20 \mathrm{~min}$ after the pairing period (Fig. $7 A$ ). In 


\begin{tabular}{llcc}
\hline \multicolumn{2}{l}{ Table 1. Electrophysiological parameters of Purkinje cells in slices } & \\
& & L7-PKCI $+/-$ & L7-PKCI- - - \\
\hline $\begin{array}{l}\text { Basal electrophysiological } \\
\text { parameters }\end{array}$ & & \\
& $V_{\mathrm{m}}(\mathrm{mV})$ & $65.6 \pm 1.0(n=8)$ & $66.4 \pm 2.3(n=5)$ \\
Climbing fiber-mediated & $R_{\text {input }}(\mathrm{M} \Omega)$ & $150 \pm 26(n=5)$ & $134 \pm 28(n=3)$ \\
EPSCs & & \\
& Amplitude (nA) & $3.5 \pm 0.3(n=21)$ & $3.3 \pm 0.5(n=9)$ \\
& Rise time (msec) & $1.16 \pm 0.03(n=21)$ & $1.23 \pm 0.10(n=9)$ \\
& Decay time constant (msec) & $7.25 \pm 0.34(n=21)$ & $7.95 \pm 1.12(n=9)$ \\
\hline
\end{tabular}

Data are expressed as mean \pm SEM. $V_{\mathrm{m}}$, Resting potential; $R_{\text {input }}$, input resistance.

contrast, the same pairing protocols applied to eight Purkinje cells obtained from five L7-PKCI mice did not induce any persistent depression of parallel fiber-mediated EPSCs; only transient depressions were observed. The mean amplitude of these responses was $95.96 \pm 4.21 \%$ of the control value $20 \mathrm{~min}$ after the pairing period (Fig. $7 B$ ). Thus, the relative changes in amplitude of parallel fiber-mediated EPSCs in wild-type mice $20 \mathrm{~min}$ after the pairing period were significantly larger than in the L7-PKCI mice (Student's $t$ test; $p<0.01$ ). Therefore, the present results show that activation of PKC is necessary for the induction of LTD not only in cultures but also in slices. Thus, although the NO-PKG pathway could be operational for the induction of LTD in slices of the L7-PKCI mutants (Daniel et al., 1998), apparently the blockage of the activation of PKC is sufficient for the blockage of LTD induction in slices.

It is possible that the LTD deficiency observed in the mutant Purkinje cells in acute slices may be caused by some effects of the L7-PKCI transgene that are independent of the direct inhibition of PKC. Because the induction of LTD is triggered by the influx of $\mathrm{Ca}^{2+}$ into Purkinje cells and by activation of mGluR1, leading to intracellular cascades involving the release of $\mathrm{Ca}^{2+}$ from inositol 1,4,5-trisphosphate $\left(\mathrm{IP}_{3}\right)$-sensitive intracellular stores through the production of $\mathrm{IP}_{3}$ (Daniel et al., 1998), we have tested whether these two crucial signaling pathways were altered in the mutant cells.

Depolarizing current pulses passed through the recording patch pipette routinely evoked depolarizing plateau potentials with combined $\mathrm{Na}^{2+}$ and $\mathrm{Ca}^{2+}$ spikes in the mutant Purkinje cells (Fig. 7C). The presence of typical $\mathrm{Ca}^{2+}$ spikes indicated that the voltage-dependent $\mathrm{Ca}^{2+}$ channels of normal Purkinje cells were at least qualitatively preserved in the L7-PKCI mice. After the plateau potential, a prolonged after-hyperpolarization (Fig. $7 C$, arrow) was always observed that was largely dependent on $\mathrm{Ca}^{2+}$, because it increased by $29.6 \pm 2.2 \%($ mean $\pm \mathrm{SEM} ; n=5)$ when calcium spikes were evoked during the plateau. Thus, the generation of a calcium-dependent after-hyperpolarization in mutant Purkinje cells after depolarization-induced spikes indicates that the $\mathrm{Ca}^{2+}$-dependent potassium conductances, which are involved in this membrane potential variation (Llinás and Sugimori, 1980), are also at least qualitatively preserved in the L7-PKCI mice.

Slow postsynaptic current recordings evoked by repetitive parallel fiber stimulation and dendritic fluorometric measurements of the intracellular $\mathrm{Ca}^{2+}$ concentration with the high-affinity $\mathrm{Ca}^{2+}$ indicator fluo3 (see Materials and Methods) were used to test the function of the mGluR1 receptor pathway in mutant Purkinje cells. As established previously (Tempia et al., 1998), brief trains of eight stimuli delivered at $100 \mathrm{~Hz}$ to parallel fibers (see Materials and Methods) routinely evoked mGluR1-mediated
EPSCs with a mean amplitude of $59 \pm 4 \mathrm{pA}($ mean $\pm \mathrm{SEM} ; n=$ 3) (Fig. 7D). These currents were blocked by bath application of $300 \mu \mathrm{M}(R S)$-1-aminoindan-1,5-dicarboxylic acid (AIDA), a selective mGluR1 antagonist. Because repetitive parallel fiber stimulation clearly evokes mGluR1-mediated EPSCs, these experiments indicate that mutant Purkinje cells express functional mGluR1 and that these currents are independent of PKC activation (see also Tempia et al., 1998). In addition, because activation of these receptors increases the $\mathrm{Ca}^{2+}$ concentration through production of $\mathrm{IP}_{3}$, we then tested the function of these receptors with fluorometric measurements of $\mathrm{Ca}^{2+}$ variations in a second series of experiments. The cells were recorded in voltage-clamp
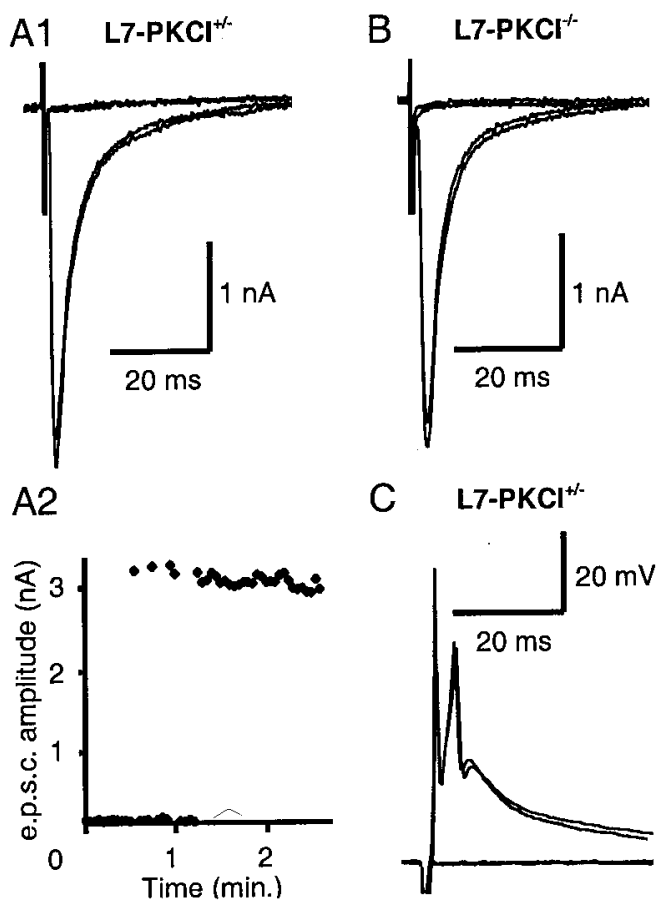

Figure 6. Mono climbing fiber innervation of Purkinje cells in 3- to 6-month-old L7-PKCI mice. A1, Two subthreshold responses and two superimposed sweeps of all-or-none climbing fiber-mediated EPSCs evoked in a mutant Purkinje cell held at a holding potential of $-80 \mathrm{mV}$, by stimulating the granular layer with progressively increasing intensity. $A 2$, Plot of amplitudes against time of climbing fiber-mediated EPSCs recorded at $-80 \mathrm{mV}$ in the same cell as in $A 1$. Stimulus intensity varied progressively in strength during the recording period. $B$, Two superimposed sweeps of all-or-none climbing fiber-mediated EPSCs and two subthreshold responses elicited in a wild-type Purkinje cell. $C$, Classical climbing fiber responses recorded in another mutant Purkinje cell. The cell was held in current clamp and the granular layer was stimulated with progressively increasing stimulus intensities. 

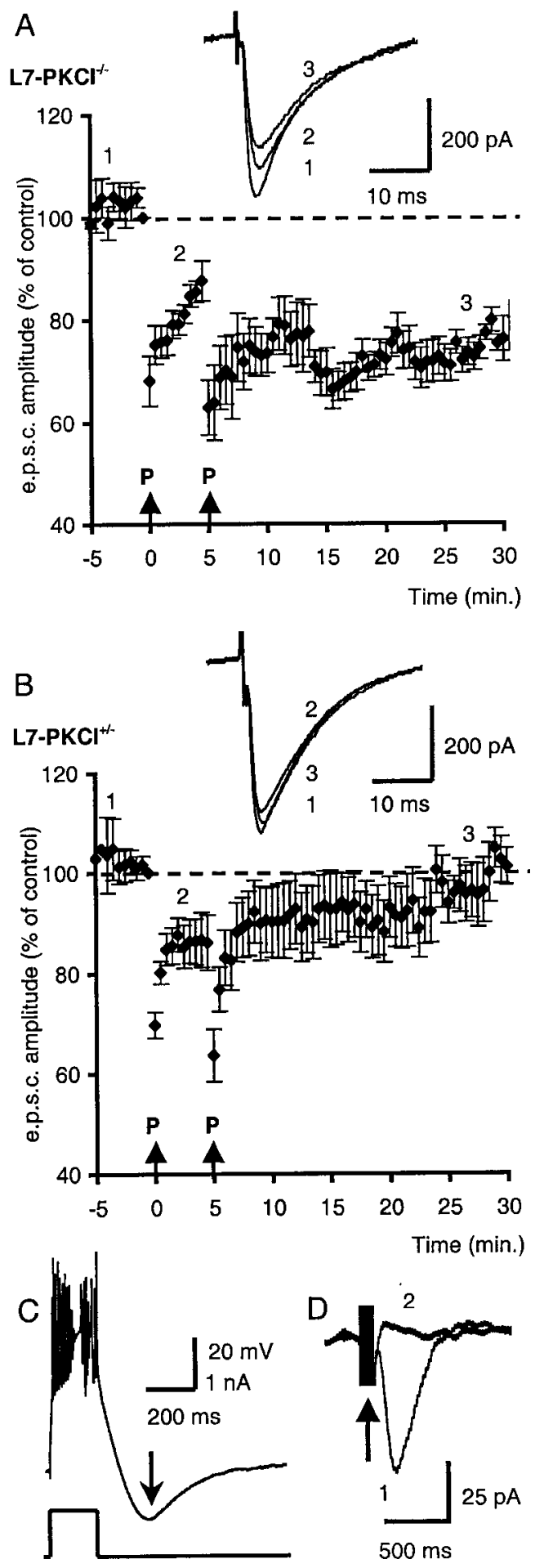

Figure 7. Induction of cerebellar LTD is suppressed in slices prepared from L7-PKCI cerebella. $A, B$, The plots represent the normalized amplitudes of parallel fiber-mediated ESPCs against time before and after two successive pairing protocols $(P)$ (see Materials and Methods) in wild-type $(A)$ and in L7-PKCI $+/-(B)$ Purkinje cells. Each point is the mean \pm SEM of separate blind experiments in nine wild-type cells $(A)$ and in eight mutant cells $(B)$. The insets show superimposed averaged EPSCs in one of the Purkinje cells recorded under control conditions (1), after the first pairing protocol (2), and during expression of LTD (3) in wild-type $(A)$ and in L7-PKCI $+/-(B)$ cells. Experiments on either wild-type or L7-PKCI mice at 3-8 weeks of age were intermingled and were done at the same time of the day. $C$, Sodium and calcium action potentials evoked by a $200 \mathrm{msec}$ depolarizing somatic current pulse in an mode at $-70 \mathrm{mV}$ and stimulated with bath-applied group I agonist $1 S, 3 R$-1-aminocyclopentane-1,3-dicarboxylic acid $(1 S, 3 R$ ACPD) $(100 \mu \mathrm{M})$, while transient fluorescence changes were used to detect transient increases in the intracellular free calcium concentration. Application of $1 S, 3 R$-ACPD induced transient changes in the proximal dendrites of mutant cells, with a mean amplitude of relative fluorescence variation $(\Delta F / F)$ of $6.1 \pm 0.4 \%$ (mean $\pm \mathrm{SEM} ; n=3$ ). In addition, removal of $\mathrm{Ca}^{2+}$ ions from the external medium failed to abolish these $1 S, 3 R$-ACPDinduced transient increases, supporting the presence of a functional mGluR1 pathway coupled to internal $\mathrm{Ca}^{2+}$ mobilization. These results were not significantly different from those recorded in wild-type cells; the mean amplitude of the $1 S, 3 R$-ACPDinduced transient was $6.3 \pm 0.3 \%$ (mean $\pm \mathrm{SEM} ; n=3 ; \Delta F / F)$.

All these data in acute slices demonstrate that the blockade of LTD induction in mutant Purkinje cells is not attributable to an indirect effect of the L7-PKCI transgene on these two signaling systems, a finding that is consistent with and that extends earlier results obtained in cultured Purkinje cells (De Zeeuw et al., 1998).

\section{DISCUSSION}

The major findings of the present study are (1) that Purkinje cell-specific inhibition of PKC leads to a blockage of LTD induction at the parallel fiber-Purkinje cell synapse in slices, (2) that a blockage of LTD induction does not lead to a disturbed baseline discharge of Purkinje cells in alert mice, and (3) that inhibition of PKC does not prevent but only delays the developmental conversion from multiple to mono climbing fiber innervation of Purkinje cells. As explained below, all of these findings are in agreement with and re-emphasize the importance of our tenet that LTD is necessary to reach a high level of motor learning in a relatively short time (De Zeeuw et al., 1998).

Consistent with earlier results obtained in the cultured Purkinje cells (De Zeeuw et al., 1998), our present data show that the specific expression of a PKC inhibitor in Purkinje cells results in an almost complete loss of cerebellar LTD in the acute slice preparation and that potential upregulation of $\mathrm{PKC}$ isoforms does not succeed in blunting the biochemical effects of the L7-PKCI transgene in situ. These findings also corroborate existing evidence that cerebellar LTD induction has an absolute requirement for the activation of PKC (Linden, 1996) and that the absence of this PKC pathway cannot be sufficiently compensated for by the NO-PKG pathway (Daniel et al., 1998).

Theoretically, it is possible that LTD was blocked by inhibition of PKC in culture but not in slices, because NO-synthetase, which is necessary for the NO-PKG pathway, is hardly present in the culture system, whereas it is readily available in the parallel fibers in slices. Such an outcome would obviously have precluded any further interpretation of the relationship between LTD induction and motor learning.

The present finding that PKC inhibition inside Purkinje cells and a consequent blockage of LTD induction do not directly corrupt their simple spike and complex spike discharge properties

L7-PKCI+/- Purkinje cell. Note the prolonged afterhyperpolarization, which follows the pulse break (arrow). D, mGluR EPSCs in L7-PKCI+/Purkinje cells evoked by repetitive parallel fiber stimulation with eight pulses at $100 \mathrm{~Hz}$ (arrow) in control saline (1), and inhibition by $300 \mu \mathrm{M}$ AIDA (2). Each trace is the average of four consecutively evoked mGluR EPSCs. 
is equally essential. If the short- and long-term dynamics of simple spike and complex activities would have been abnormal in the L7-PKCI mutants, their impaired motor learning might have reflected a secondary abnormality of their Purkinje cells attributable to, for example, an aberration of one of the kinaseregulated ion channels rather than to a direct lack of LTD itself.

Although cerebellar LTD may be necessary for certain forms of associative motor learning, it is unclear so far whether LTD is essential for the maturation of motor coordination during development. A general assumption is that Purkinje cells may initially receive an abundance of inappropriate or even erroneous parallel fiber inputs that need to be attenuated to develop a normal level of motor performance. However, the fact that simple spike firing rates in LTD-deficient L7-PKCI mice are indistinguishable from those in their wild-type littermates suggests that LTD probably does not contribute much to this process. If this were the case, one would expect a reduction of baseline simple spike activity in wild-type mice because the excitability of their Purkinje cells to spontaneous parallel fiber inputs would be attenuated because of the long-term synaptic depression. Our findings suggest therefore that cerebellar LTD may be used only for short-term adaptation, whereas other mechanisms, perhaps in multiple brain areas, may serve to store and retrieve information required for long-term adaptation and maturation of motor control during development. This view is supported by the observation that L7-PKCI mice do not exhibit general motor coordination deficits, whereas rapid adaptation of their VOR after a few hours of visuovestibular training is impaired (De Zeeuw et al., 1998). Thus, apparently these LTD-deficient mice show deficient motor learning in the short term, but in the long term they have other sufficient learning mechanisms that allow them to obtain a normal motor performance with normal dynamics of their simple spike and complex spike responses.

An interesting hypothesis proposed by De Schutter (1995) is that cerebellar LTD might act to keep the simple spike rate of Purkinje cells within its physiological range. Because the inhibitory circuitry onto Purkinje cells is to a large extent feedforward, LTD could be the missing negative feedback mechanism preventing overexcitation of Purkinje cells by their large number of parallel fiber inputs. In this hypothesis, coactivation of adjacent parallel fiber synapses alone would cause local increases in the $\mathrm{Ca}^{2+}$ concentration that would be sufficient to induce LTD at the activated synapses, without the need for conjunctive complex spikes. However, our present data show that blocking the activation of $\mathrm{Ca}^{2+}$-dependent PKC does not lead to hyperactivity of Purkinje cells. Instead, both the shortand long-term dynamics of simple spike firing in Purkinje cells of alert wild-type and L7-PKCI mutant mice are indistinguishable. We conclude therefore that cerebellar LTD is not critically involved in normalizing simple spike rates in the long run, and thus probably is not operating as a protective mechanism as proposed by De Schutter (1995).

Although the L7-PKCI mutant shows normal simple spike and complex spike discharge properties as well as normal motor performance, other mutants can be found with both abnormal Purkinje cell responses and coordination deficits. For example, Schiffman et al. (1999) reported that mice lacking the $\mathrm{Ca}^{2+}$ binding protein calretinin exhibit impaired motor coordination, and that the simple spike frequency, complex spike duration, and climbing fiber pause of their Purkinje cells are severely affected in vivo. Interestingly, no profound alterations were observed in the slice preparation of these knock-out mice, suggesting that calreti- nin primarily plays a major role at the network level. For example, the climbing fiber pause probably results from a direct postexcitational inactivation of the Purkinje cell membrane combined with the potential impact of the climbing fiber collaterals on cortical interneurons such as the Golgi cells and basket cells, which can directly inhibit the transmission in the mossy fibergranule cell pathway and the output of Purkinje cells, respectively (Armstrong, 1974; Simpson et al., 1996). In contrast to the calretinin knock-outs, the L7-PKCI mutants showed no abnormalities in their complex spike-simple spike intervals, including the climbing fiber pauses. Thus, a blockage of LTD induction does not, unlike impairment in $\mathrm{Ca}^{2+}$ homeostasis, disturb the basal firing properties of the cerebellar circuitry.

Climbing fiber inputs play a central role in the Marr-Albus-Ito theories of cerebellar motor learning (Simpson et al., 1996). They are thought to guide the learning process by signaling errors in performance (Ito, 1989). In the L7-PKCI mutant, multiple climbing fiber innervation has been the only developmental abnormality that could be identified (De Zeeuw et al., 1998). Interestingly, however, our present results demonstrate that the multiple climbing fiber innervation found in younger L7-PKCI mutants $(<3$ months of age) does not persist in older animals $(>3$ months of age). Because VOR adaptation is impaired in both younger and older adult animals (De Zeeuw et al., 1998), we conclude that the impaired motor learning observed in L7-PKCI mice is not caused by an abnormal climbing fiber innervation of the Purkinje cells.

Persistent multiple climbing fiber innervation has been suggested to underlie impaired motor coordination in PKC $\gamma$ knockouts (Chen et al., 1995). This association is supported by the impaired motor coordination found in mGluR1- (Aiba et al., 1994; Conquet et al., 1994), GluR82- (Kashiwabuchi et al., 1995), and G $\alpha$ q- (Offermans et al., 1997) knock-out mice, which all have a multiple climbing fiber innervation. Yet our data obtained from L7-PKCI mice that are $<3$ months of age are at odds with this association, because these animals show a multiple climbing fiber innervation but no signs of ataxia and no motor coordination deficits (De Zeeuw et al., 1998). Potentially because of a different gene regulation of the $\mathrm{L} 7$ promotor, the level of multiple climbing fiber innervation in the L7-PKCI mutant may not be as robust as that in the global knock-outs described above. This difference may also explain why triple climbing fiber innervation can be observed in, for example, the PKC $\gamma$ knock-out (Kano et al., 1995) but not in the L7-PKCI mutant, and why the multiple climbing fiber innervation in the L7-PKCI mutant apparently does not persist as long as in the other knock-outs.

In conclusion, we state that the present findings are the first to show that a blockade of cerebellar LTD induction, as currently assessed in slices, does not by itself lead to major disturbances in Purkinje cell physiology in vivo, and that the impaired motor learning as observed in the older LTD-deficient L7-PKCI mutants cannot be due either to a disturbance in the baseline simple spike and complex spike activities of their Purkinje cells or to a persistent multiple climbing fiber innervation. These data all support our tenet that cerebellar LTD facilitates fast motor training, but at the same time our findings also indicate the restrictions of cerebellar LTD in that it cannot be the only mechanism for learning.

\section{REFERENCES}

Aiba A, Kano M, Chen C, Stanton ME, Fox GD, Herrup K, Zwingman TA, Tonegawa S (1994) Deficient cerebellar long-term depression and impaired motor learning in mGluR1 mutant mice. Cell 79:377-388. 
Armstrong DM (1974) Functional significance of connections of the inferior olive. Physiol Rev 54:358-417.

Batchelor A, Garthwaite J (1997) Frequency detection and temporally dispersed synaptic signal association through a metabotropic glutamate receptor pathway. Nature 385:74-77.

Chen C, Kano M, Chen L, Bao S, Kim JJ, Hashimoto K, Thompson RF, Tonegawa S (1995) Impaired motor coordination correlates with persistent multiple climbing fiber innervation in PKC $\gamma$ mutant mice. Cell 83:1233-1242.

Conquet F, Bashir ZI, Davies CH, Daniel H, Ferraguti F, Bordi F, Franz-Bacon K, Reggian A, Matarerse V, Conde F, Collingridge GL (1994) Motor deficit and impairment of synaptic plasticity in mice lacking mGluR1. Nature 372:237-242.

Cox DR (1962) Renewal theory. London: Methuen.

Crépel F, Jaillard D (1991) Pairing of pre- and postsynaptic activities in cerebellar Purkinje cells induces long-term changes in synaptic efficacy: an in vitro study. J Physiol (Lond) 432:123-141.

Daniel H, Levenes C, Crépel F (1998) Cellular mechanisms of cerebellar LTD. Trends Neurosci 21:401-407.

Daniel H, Levenes C, Fagni L, Conquet F, Bockaert J, Crépel F (1999) Inositol-1,4,5-trisphosphate-mediated rescue of cerebellar long-term depression in subtype 1 metabotropic glutamate receptor mutant mouse. Neuroscience 92:1-6.

De Schutter E (1995) Cerebellar long-term depression might normalize excitation of Purkinje cells: a hypothesis. Trends Neurosci 18:291-295.

De Zeeuw CI, Hansel C, Bian F, Koekkoek SKE, van Alphen AM, Linden DJ, Oberdick J (1998) Expression of a protein kinase C inhibitor in Purkinje cells blocks cerebellar LTD and adaptation of the vestibulo-ocular reflex. Neuron 20:495-508.

Eggermont JJ (1990) The correlative brain (Braitenberg V, ed). New York: Springer.

Funabiki K, Mishina M, Hirano T (1995) Retarded vestibular compensation in mutant mice deficient in $\delta 2$ glutamate receptor subunit. NeuroReport 7:189-192.

Gabbiani F, Koch C (1998) Principles of spike train analysis. In: Methods in neuronal modeling, Ed 2 (Koch C, Segev I, eds), pp 313-360. Cambridge, MA: MIT.

Ichise T, Kano M, Hashimoto K, Yanagihara D, Nakao K, Shigemoto R, Katsuki M, Aiba A (2000) mGluR1 in cerebellar Purkinje cells is essential for long-term depression, synapse elimination, and motor coordination. Science 288:1832-1835.

Ito M (1989) Long-term depression. Annu Rev Neurosci 12:85-102.

Ito M, Jastreboff PJ, Miyashita Y (1982) Specific effects of unilateral lesions in the flocculus upon eye movements in albino rabbits. Exp Brain Res 45:233-242.

Kano M, Hashimoto K, Chen C, Abeliovich A, Aiba A, Kurihara H, Watanabe M, Inoue YL, Tonegawa S (1995) Impaired synapse elimination during cerebellar development in $\mathrm{PKC} \gamma$ mutant mice. Cell 83:1223-1231.

Kashiwabuchi N, Ikeda K, Araki K, Hirano T, Shibuki K, Tkayama C, Inoue YL, Kutsuwada T, Yagi T, Kang Y (1995) Impairment of motor coordination, Purkinje cells synapse formation, and cerebellar longterm depression in GluR $\delta 2$ mutant mice. Cell 81:245-252.

Konnerth A, Llano I, Armstrong CM (1990) Synaptic currents in cerebellar Purkinje cells. Proc Natl Acad Sci USA 87:2662-2665.
Lang EJ, Sugihara I, Llinas R (1997) Differential roles of apamin- and charybdotoxin-sensitive $\mathrm{K}^{+}$conductances in the generation of inferior olive rhythmicity in vivo. J Neurosci 17:2825-2838.

Lev-Ram V, Jiang T, Wood J, Lawrence DS, Tsien RY (1997) Synergies and coincidence requirements between NO, cGMP, and $\mathrm{Ca}^{2+}$ in the induction of cerebellar long-term depression. Neuron 18:1025-1038.

Linden DJ (1996) Cerebellar long-term depression as investigated in a cell culture preparation. Behav Brain Sci 19:339-346.

Linden DJ, Connor JA (1995) Long-term synaptic depression. Annu Rev Neurosci 18:319-357.

Lisberger SG (1998) Cerebellar LTD: a molecular mechanism of behavioral learning? Cell 92:701-704.

Llano I, Marty A, Armstrong CM, Konnerth A (1991) Synaptic- and agonist-induced excitatory currents of Purkinje cells in rat cerebellar slices. J Physiol (Lond) 434:183-213.

Llinás R, Sugimori M (1980) Electrophysiological properties of in vitro Purkinje cell somata in mammalian cerebellar slices. J Physiol (Lond) 305:171-195.

McDevitt CJ, Ebner TJ, Bloedel JR (1982) The changes in Purkinje cell simple spike activity following spontaneous climbing fiber inputs. Brain Res 237:484-491.

Mountcastle VB, Talbot WH, Sakata H, Hyvarinen J (1969) Cortical neuronal mechanisms in flutter-vibration studies in unanesthetized monkeys: neuronal periodicity and frequency discrimination. J Neurophysiol 32:452-484.

Nelson TJ, Cavallaro S, Yi CL, McPhie D, Schreurs BG, Gusev PA, Favit A, Zohar O, Kim J, Beushausen S, Ascoli G, Olds J, Neve R, Alkon DL (1996) Calexcitin: a signaling protein that binds calcium and GTP, inhibits potassium channels, and enhances membrane excitability. Proc Natl Acad Sci USA 93:13808-13813.

Offermans S, Hashimoto K, Watanabe M, Sun W, Kurihara H, Thompson RF, Inoue Y, Kano M, Simon MI (1997) Impaired motor coordination and persistent multiple climbing fiber innervation of cerebellar Purkinje cells in mice lacking G $\alpha$ q. Proc Natl Acad Sci USA 94:14089-14094.

Press WH, Flannery BP, Teukolsky SA, Vettering WT (1992) Numerical recipes in C, Ed 2. Cambridge, MA: Cambridge UP.

Sato Y, Miura A, Fushiki H, Kawasaki T (1992) Short-term modulation of cerebellar Purkinje cell activity after spontaneous climbing fiber input. J Neurophysiol 68:2051-2062.

Schiffmann SN, Cheron G, Lohof A, d'Alcantara P, Meyer M, Parmentier M, Schurmans S (1999) Impaired motor coordination and Purkinje cell excitability in mice lacking calretinin. Proc Natl Acad Sci USA 96:5257-5262.

Shibuki K, Gomi H, Chen L, Bao S, Kim JJ, Wakatsuki H, Fujisaki T, Fujimoto K, Katoh A, Ikeda T, Chen C, Thompson RF, Itohara S (1996) Deficient cerebellar long-term depression, impaired eyeblink conditioning, and normal motor coordination in GFAP mutant mice. Neuron 16:587-599.

Simpson JI, Wylie DR, De Zeeuw CI (1996) On climbing fiber signals and their consequences. Behav Brain Sci 19:380-394.

Tempia F, Miniaci CM, Anchisi D, Strata P (1998) Postsynaptic current mediated by metabotropic glutamate receptors in cerebellar Purkinje cells. J Neurophysiol 80:520-528. 